\title{
Marine boundary layer simulation and verification during BOBMEX-Pilot using NCMRWF model
}

\author{
SWATI BASU \\ National Centre for Medium Range Weather Forecasting, INSAT Building, Mausam Bhavan Complex, Lodi \\ Road, New Delhi, India \\ email:swati@ncmrwf.gov.in
}

\begin{abstract}
A global spectral model (T80L18) that is operational at NCMRWF is utilized to study the structure of the marine boundary layer over the Bay of Bengal during the BOBMEX-Pilot period. The vertical profiles of various meteorological parameters within the boundary layer are studied and verified against the available observations. The diurnal variation of various surface fields are also studied. The impact of non-local closure scheme for the boundary layer parameterisation is seen in simulation of the flow pattern as well as on the boundary layer structure over the oceanic region.
\end{abstract}

\section{Introduction}

Analysis of the marine boundary layer structure and the air sea interaction processes are crucial and very important in understanding the general flow pattern over the Indian subcontinent including the genesis of lows and depressions. It remains then essential that the boundary layer structure as simulated by the numerical models should be reproduced in the most realistic manner. The marine boundary layer plays a key role in the atmospheric energy exchange processes. As distinguished from most land surfaces, open sea and ocean surfaces are characterized by a remarkable temporal and spatial homogeneity of temperature. This is primarily due to the large heat capacity and efficient mixing processes in the upper oceanic mixed layer. Thus, over much of the ocean, the surface heat flux does not play a large role in determining the boundary layer structure. Observational validation of boundary layer theory, details of boundary layer structure rely heavily on data which is relatively sparse and especially rare in the case of marine boundary layer. Few observational studies are available on the marine boundary layer over the Indian Ocean. BOBMEX offered an opportunity to explore the structure of the marine boundary layer and its evolution over the Bay of Bengal.

\section{Synoptic conditions}

The Pilot experiment was carried out on board ORV Sagar Kanya. The ship left Mormugao on 23rd October 1998, moved towards south almost parallel to the west coast of India up to $5^{\circ} \mathrm{N}$, and then turned eastwards. The first stationary (drifting) time series station was at $7^{\circ} \mathrm{N} 87^{\circ} \mathrm{E}$ for two days (October 30th, $31 \mathrm{st})$, the second time series station was at $10^{\circ} \mathrm{N} 87^{\circ} \mathrm{E}$ for two days (2nd - 3rd November). During the period for which the Pilot data was obtained (1st and 3rd November 1998), a shear zone was seen over south Bay of Bengal on 1st November in which a low pressure formed on 2nd November in southwest Bay off Srilanka-south Tamilnadu coast. This low pressure persisted over the same area till 6th November and became less marked on 7th November. The operational model at NCMRWF (OPER) was run with the initial condition of 1st November 1998 and the forecasts of three days were obtained. Similar forecasts were also obtained with the NCMRWF model having a different parameterisation scheme for the boundary layer viz. non-local closure scheme (NLC). The flow pattern as well as the precipitation pattern were obtained and compared with the observational analysis using both the schemes. The profiles of temperature and humidity as obtained from Sagar Kanya

Keywords. Marine boundary layer; parameterisation; BOBMEX; non-local closure; global model. 
were also compared with those obtained from both the models. Since the difference between both the models lies in the parameterisation scheme of the boundary layer only, the impact of the different schemes for the boundary layer could readily be identified.

\section{Description of the schemes}

\subsection{PBL parameterisation scheme of NCMRWF model}

A short description of the model, which is run on an operational basis at NCMRWF, is given in Basu et al (1999). The standard PBL parameterisation uses a first-order closure approximation whereby the turbulent fluxes are correlated to the mean vertical gradients through the eddy diffusivities. These eddy diffusivities are stability dependent (depending upon the bulk Richardson number) and are determined through mixing length considerations. It is assumed that the mixing length $l$ varies as $k z$ ( $k$ being the von karman constant and $z$ the height above the ground) close to the ground, but approaches constant value $\lambda(=250 \mathrm{~m})$ at greater heights. Thus, the eddy diffusivities are determined through: $K=l^{2} S|\partial v / \partial z|$; where $l$ is the mixing length given by

$$
l=k z /(1+k z / \lambda) .
$$

Here, $S$ is a set of semi-empirical stability functions dependent upon the bulk Richardson number $R$, and $\lambda$ is the limiting mixing length.

\subsection{Parameterisation using the non local closure scheme}

There are certain limitations of the mixing length theory (Stull 1984) the most important being its inability to represent realistically mixing in the convective boundary layer involving the "counter gradient fluxes" ( Troen and Mahrt 1986; Hong and Pan 1989). One of the alternatives is to go to higher order closure approaches but they were computationally more expensive. Moreover, Ayotte (1996) showed that these schemes were in the strictest sense local diffusion schemes and had a strong tendency to underentrain in the presence of a strong capping inversion. Recently an alternative approach has been suggested, the so called non-local $K$ closure which is computationally efficient and has the capability to represent large eddy turbulence within a well mixed boundary layer. This scheme (Hong and Pan 1989; Troen and Mahrt 1986) has been widely tested for general circulation models as well as numerical prediction models with further generalization and reformulation (Holtslag et al 1990). In the present study, the scheme that is used is after Hong and Pan (1989), where the turbulence diffusion equations for prognostic variables $(C ; u, v, q, q)$ are expressed by

$$
\delta_{c} / \delta_{t}=\delta / \delta_{z}\left[K_{c}\left(\delta_{c} / \delta_{z}-\gamma_{c}\right)\right]
$$

where $K_{c}$ is the eddy diffusivity coefficient and $\gamma_{c}$ is a correction to the local gradient that incorporates the contribution of the large scale eddies to the total flux. The diffusivity coefficient in the mixed layer is given by

$$
K_{m}=k w_{s} z(1-z / h)_{p}
$$

where $p$ is the profile shape exponent, $w_{s}$ is the mixed layer velocity scale, $h$ is the PBL height and $k$ is the von karman constant. The PBL height is given by

$$
h=R_{i b} \frac{\theta_{v a}|U(h)|^{2}}{g\left(\theta_{v}(h)-\theta_{s}\right)}
$$

where $R_{i b}$ is the critical bulk Richardson number, $U(h)$ is the horizontal wind speed at $h, \theta_{v a}$ is the virtual potential temperature at the lowest model level $\theta_{v}(h)$ is the virtual potential temperature at $h$ and $\theta_{s}$ is the appropriate surface temperature. For the free atmosphere, however, the local $K$ approach is utilized.

\section{Results}

Figures 1(a), (b) and (c) show the flow pattern as seen in the analysis and day 2 forecasts from OPER and NLC respectively valid for 3rd November 1998. As mentioned in the previous section a low pressure area had formed around $87^{\circ} \mathrm{E} 10^{\circ} \mathrm{N}$ on 2 nd November which persisted till 6th November. As seen both OPER and NLC were able to predict the circulation over Bay of Bengal (around $87^{\circ} \mathrm{E} 10^{\circ} \mathrm{N}$ ) although OPER showed intense circulation compared to analysis which shows only a sheared zone. Both the models show two closed circulations over the Bay as well as over the Arabian Sea unlike the analysis which showed an extended shear zone over the Arabian Sea. In general both the models show similar flow patterns for all the forecast days. Figure 2 (a)-(c) shows the observed analysed rainfall (Mitra et al 1997) and 2448 hour accumulated precipitation valid for 3rd November 1998 with OPER and NLC respectively. In general it is seen that OPER shows more rainfall over southeast Bay which is not observed. This may be due to the fact that OPER enhances the flow pattern over the Bay as was seen in figure 1. NLC on the other hand shows a reasonable amount of rainfall over the Bay. The rainfall over southern peninsula is however better simulated in OPER compared to NLC although the observed rainfall is higher (about three times). The rainfall patch in the adjoining part of north Sri Lanka has not been shown by either models. Figures $3-5$ show the various profiles in the boundary layer at $87^{\circ} \mathrm{E} 10^{\circ} \mathrm{N}$ at four different time intervals corresponding to dates 1st and 3rd November 1998. 
(a)

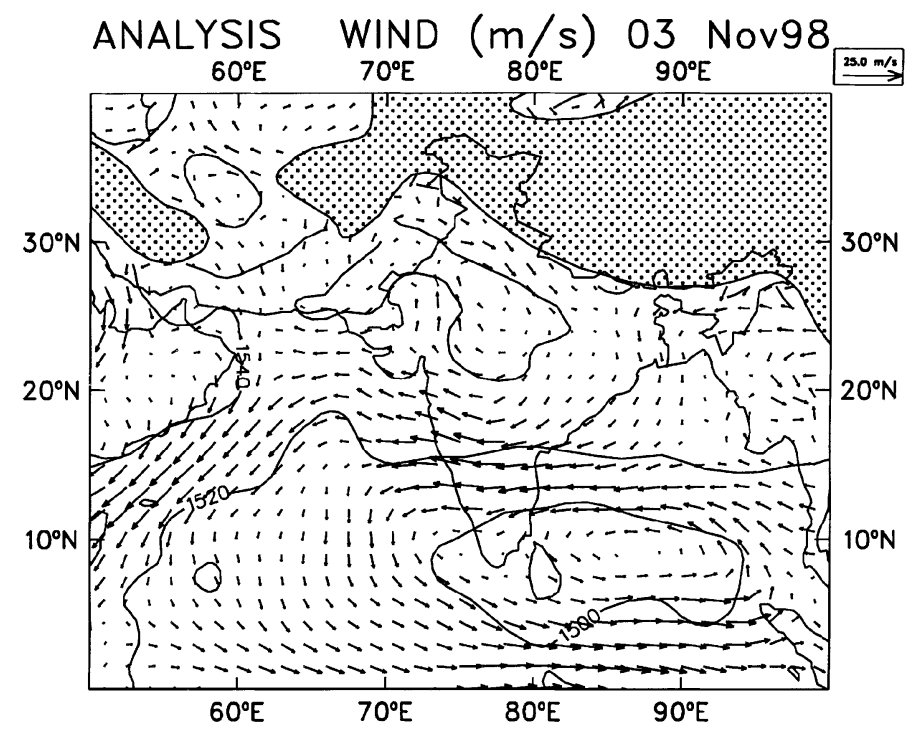

(b)

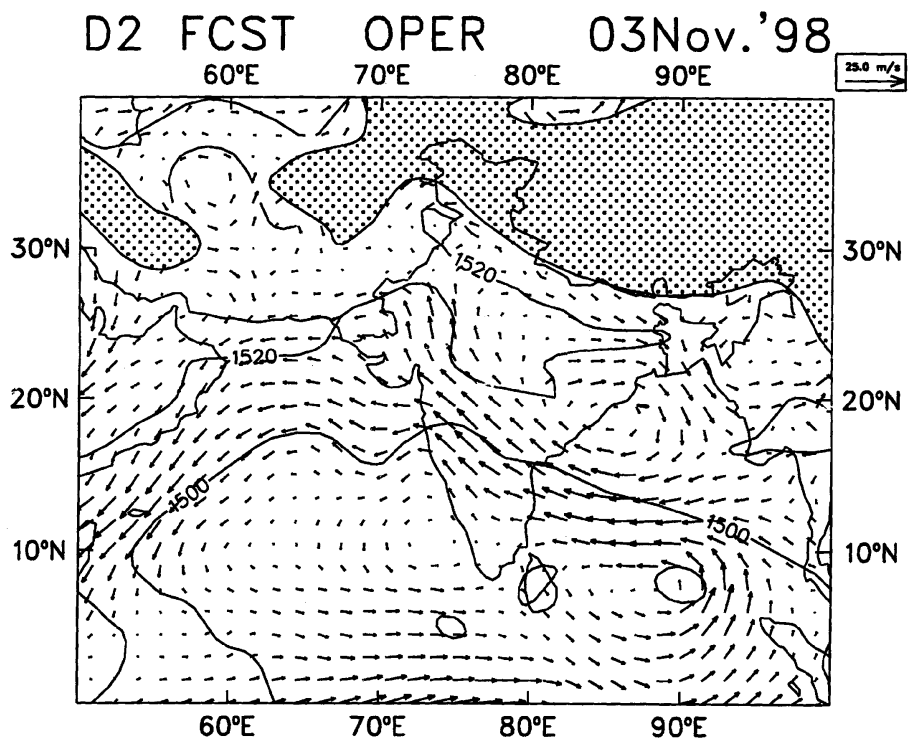

(c)

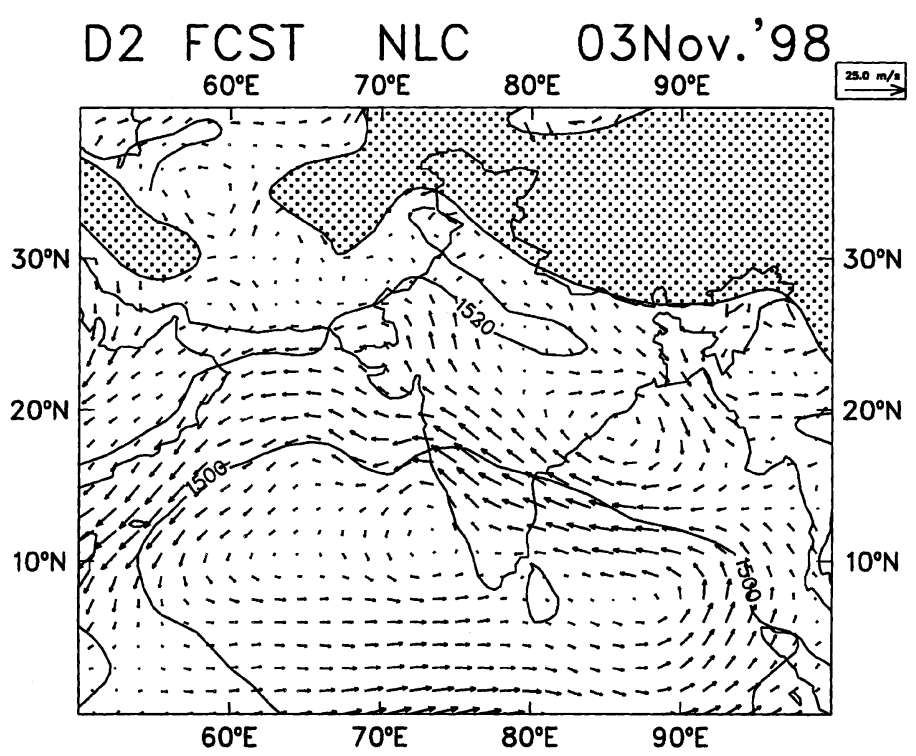

Figure 1. Geographical distribution of $850 \mathrm{hPa}$ wind vectors $\left(\mathrm{ms}^{-1}\right)$ and geopotential heights $(\mathrm{m})$ over the monsoon region for 3rd November 1998 (a) Verifying analysis; (b) $48 \mathrm{hr}$ forecast by OPER; (c) $48 \mathrm{hr}$ forecast by NLC. 
(a)

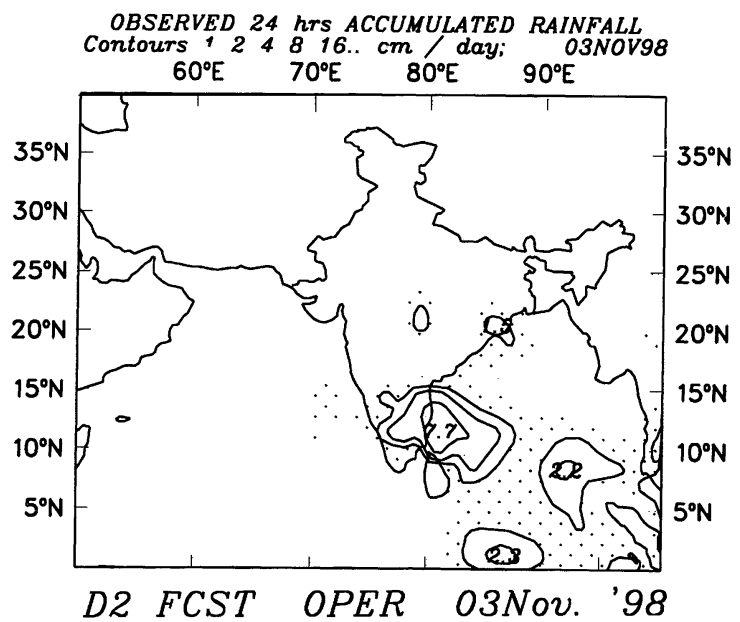

(b)

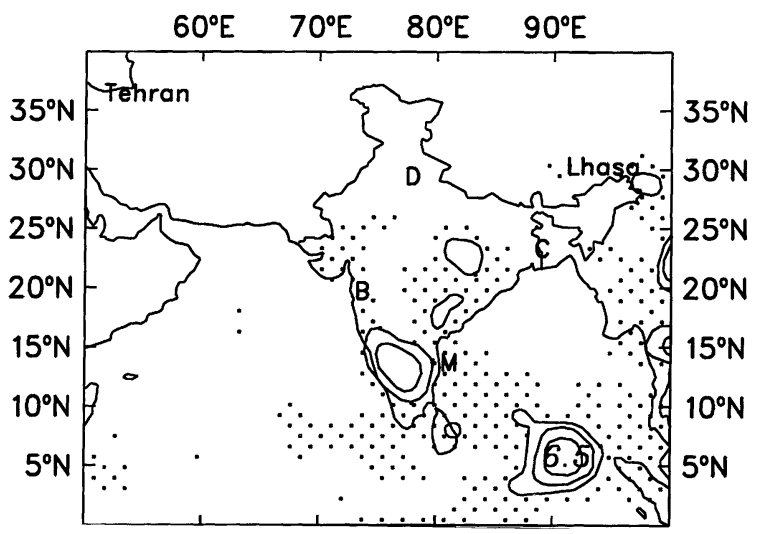

(c)

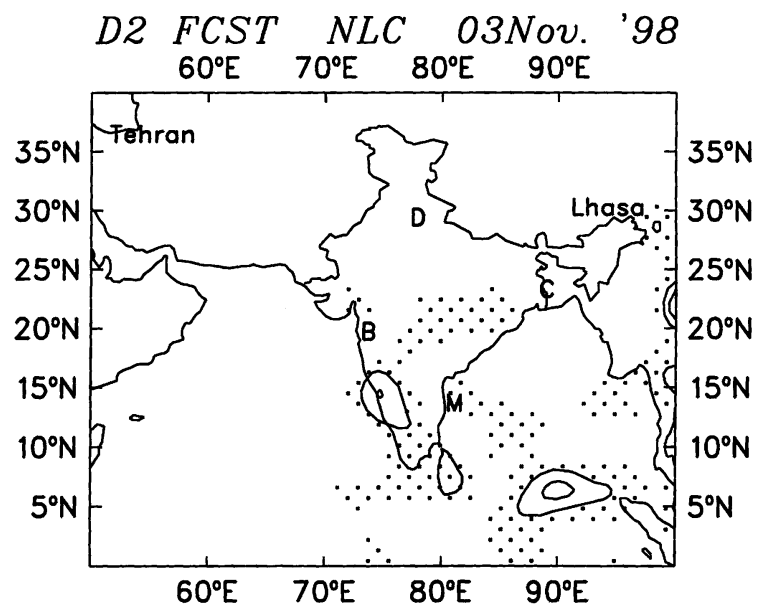

Figure 2. Geographical distribution of accumulated $48-72 \mathrm{hr}$, precipitation in $\mathrm{cm} /$ day for 3rd November 1998 over the Indian region and adjoining areas (min. contour $1 \mathrm{~cm}$ ) shaded areas represent precipitation $<1 \mathrm{~cm}$. (a) Analysed rainfall from INSAT and rain gauge; (b) $48 \mathrm{hr}$ forecast by OPER; (c) $48 \mathrm{hr}$ forecast by NLC.

The profiles of humidity and temperatures as simulated by the model with the initial condition of 1 st November 1998 valid for different forecast hours are compared with the observations. During the period of comparison, it was noted that 1st November was cloudy and rainy compared to 3rd November which was a relatively clear day. The temperature profile in figure 3 which is valid for 1st November 1999 at 0700 hours suggests that the mixed layer depth is relatively shallower and extends up to $1000 \mathrm{~m}$. The maximum wind speed is around $10 \mathrm{~ms}^{-1}$ and the humidity is quite high. It is seen that although the profiles of the humidity are comparing well with the observations till about $890 \mathrm{hPa}$, the magnitudes are smaller by both the models. Both the models are unable to simulate the higher values of humidity above $890 \mathrm{hPa}$. The profiles obtained from both NLC and OPER are comparable with each other except for the diffusivity 

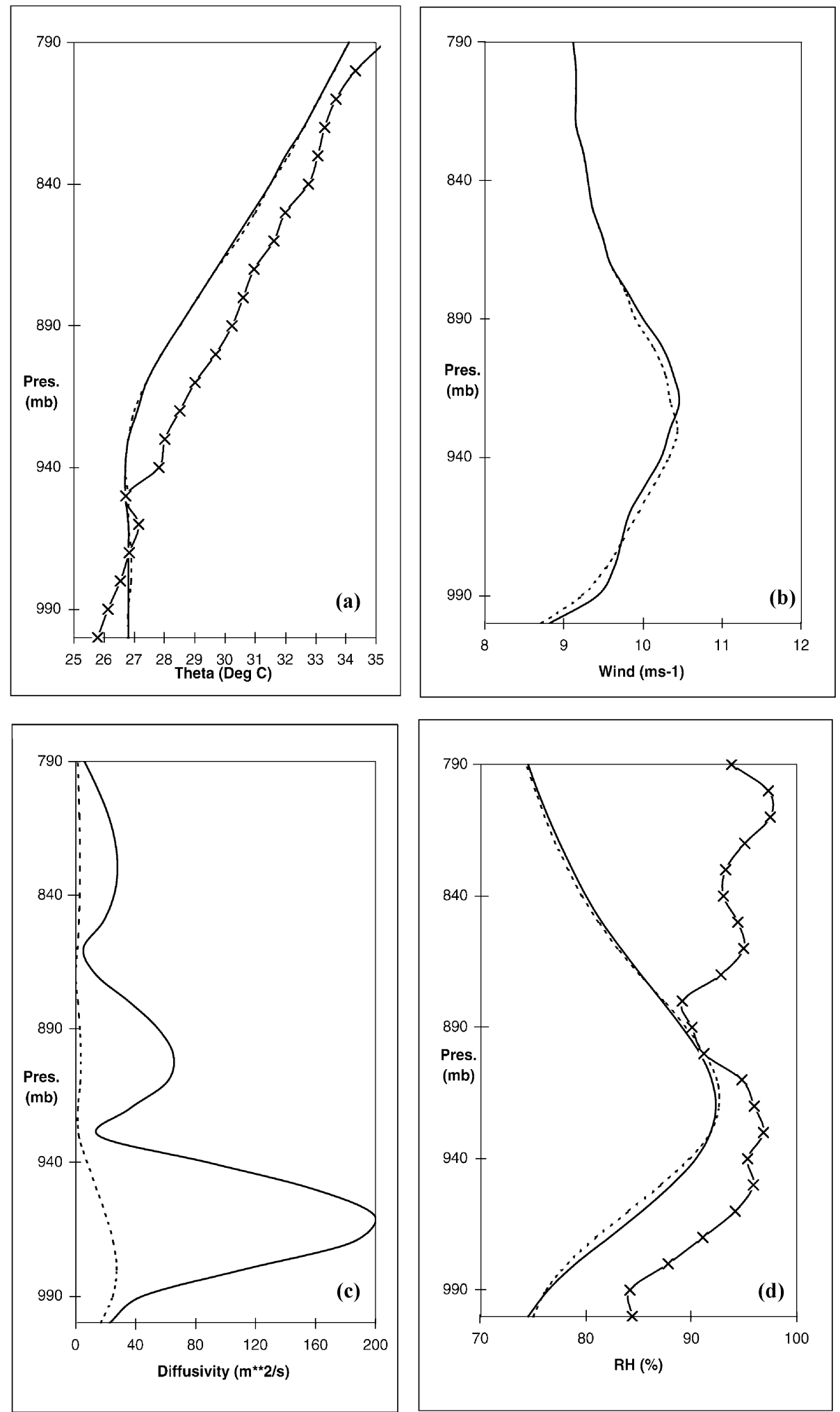

Figure 3. Vertical profiles valid for $0700 \mathrm{hrs}$ of 1 st November 1998 . Profiles till $790 \mathrm{hPa}$ at $87^{\circ} \mathrm{E} 10^{\circ} \mathrm{N}$. Comparison with model forecast with IC: 1st November 199800 hrs. (a) Theta profile; (b) wind profile; (c) Diffusivity profile; (d) Relative humidity profile; - OPER; ---- NLC; --x---X---X---x Observations.

profile which shows higher values for OPER at the lower levels. Figure 4 shows similar profiles valid for 3rd November $0700 \mathrm{hrs}$. This day was a clear day which gets reflected in the temperature profile that shows mixing till a higher level. The wind speeds are also higher. However, the wind speed simulated by NLC is lower compared to OPER. The magnitude of the humidity simulated by both the models are higher compared to the observations above 400 meters. The humidity generated by NLC at lower levels is higher 
(a)

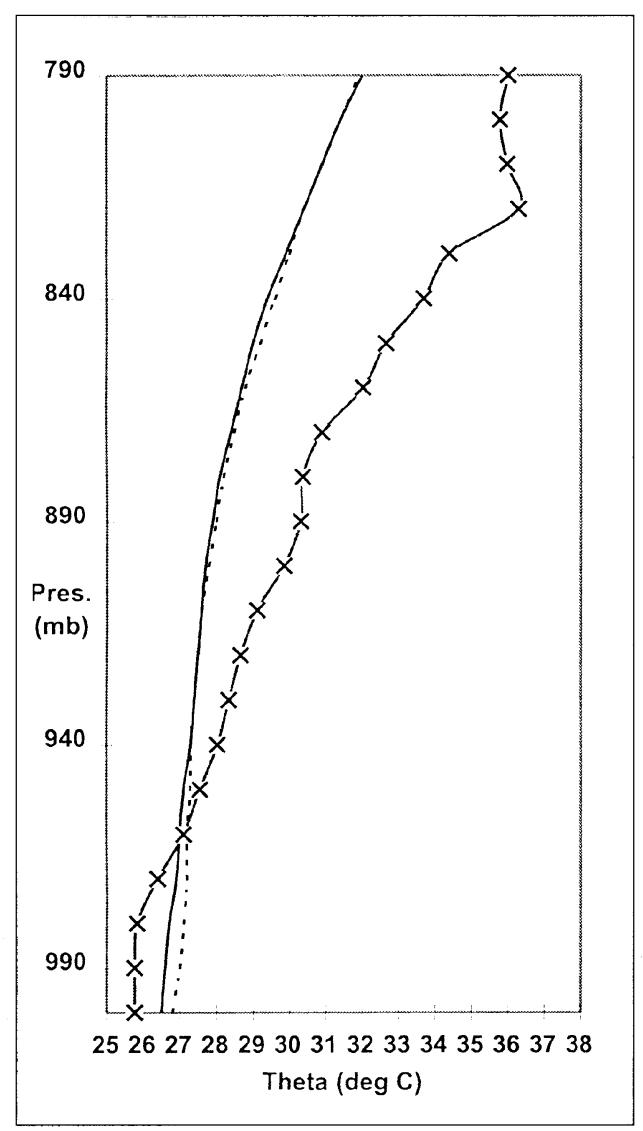

(c)

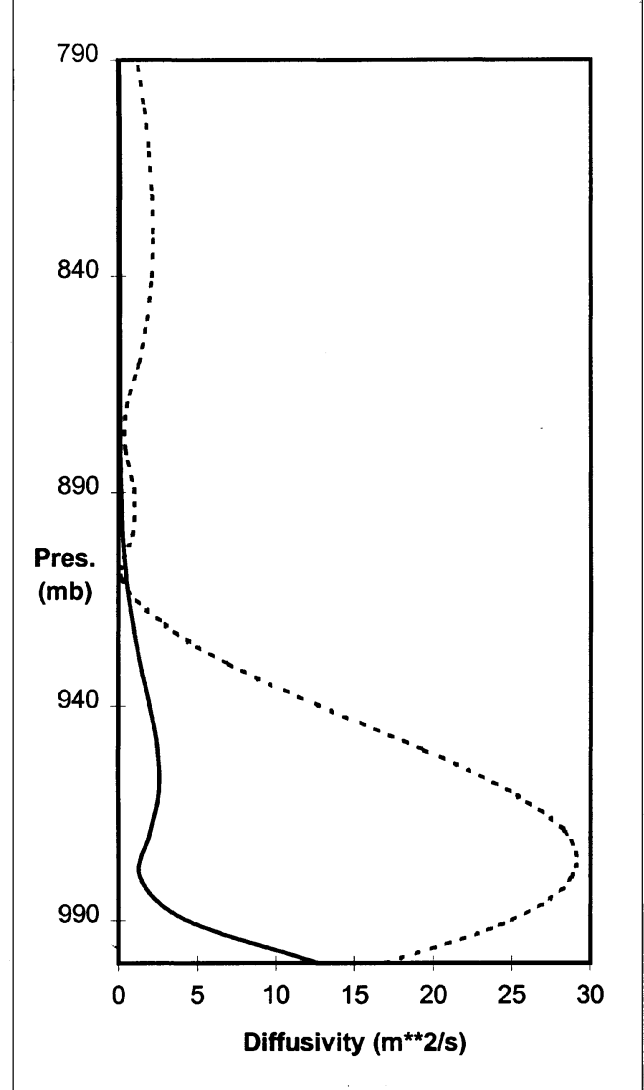

(b)

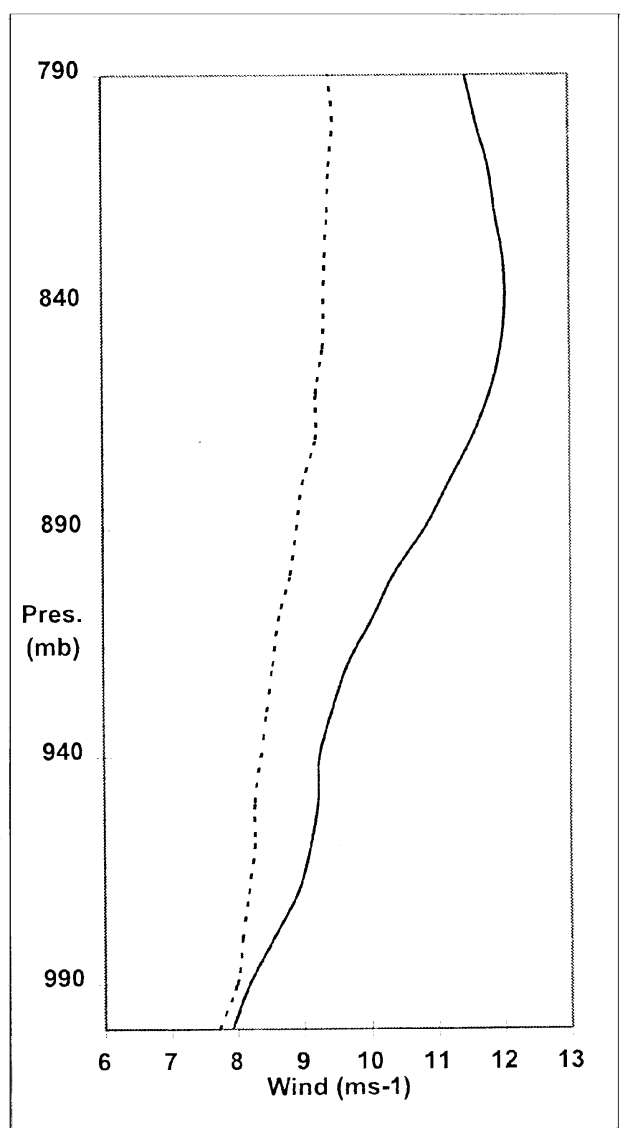

(d)

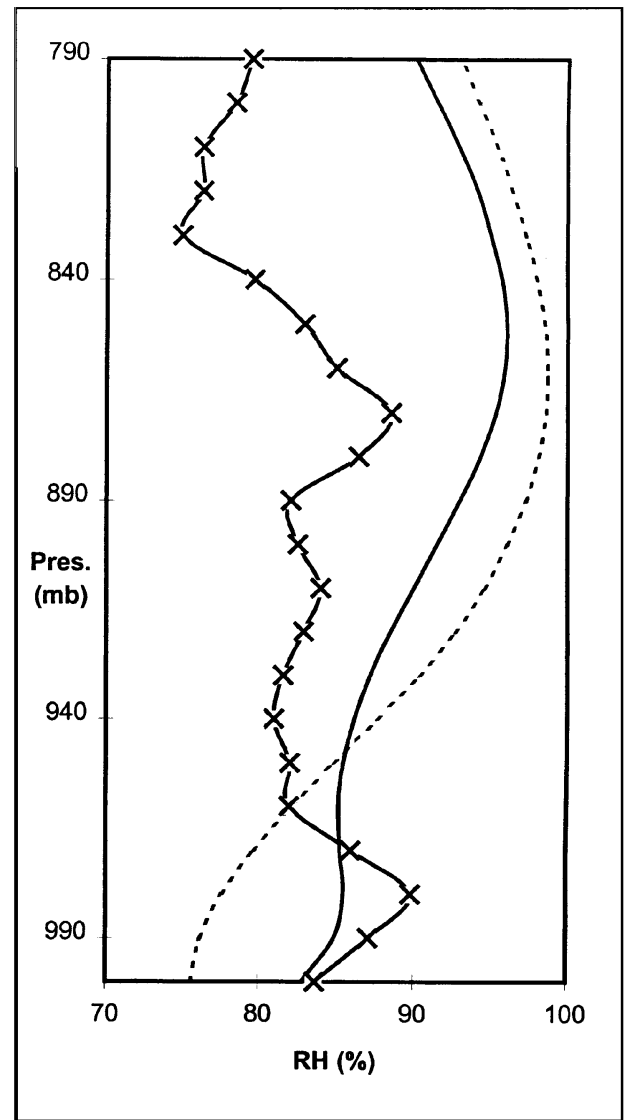

Figure 4. Vertical profiles valid for $0700 \mathrm{hrs}$ of $3 \mathrm{rd}$ November 1998. Profiles till $790 \mathrm{hPa}$ at $87^{\circ} \mathrm{E} 10^{\circ} \mathrm{N}$. Comparison with model forecast with IC: 1st November $199800 \mathrm{hrs}$. (a) Theta profile; (b) Wind profile; (c) Diffusivity profile; (d) Relative Humidity profile; - OPER; - --- NLC; --x---X---X---x Observations. 


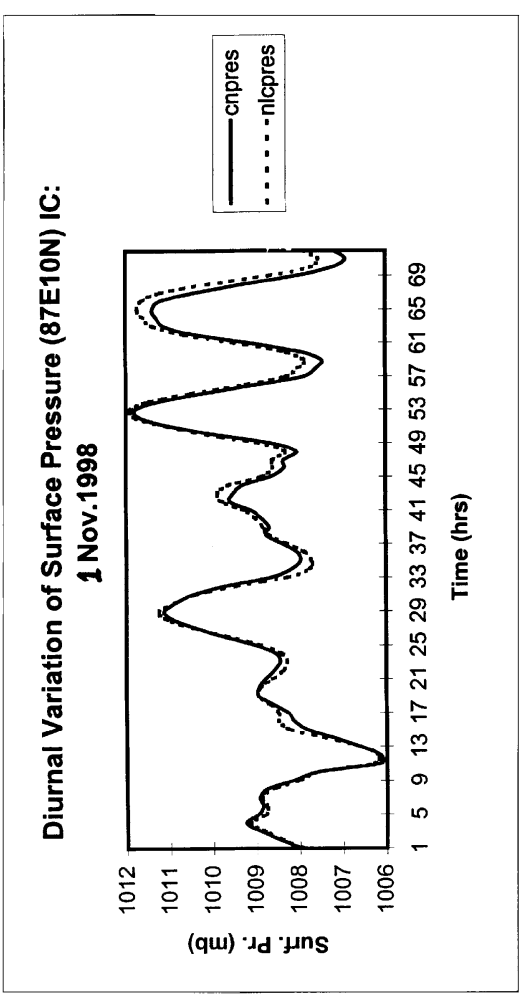

อ

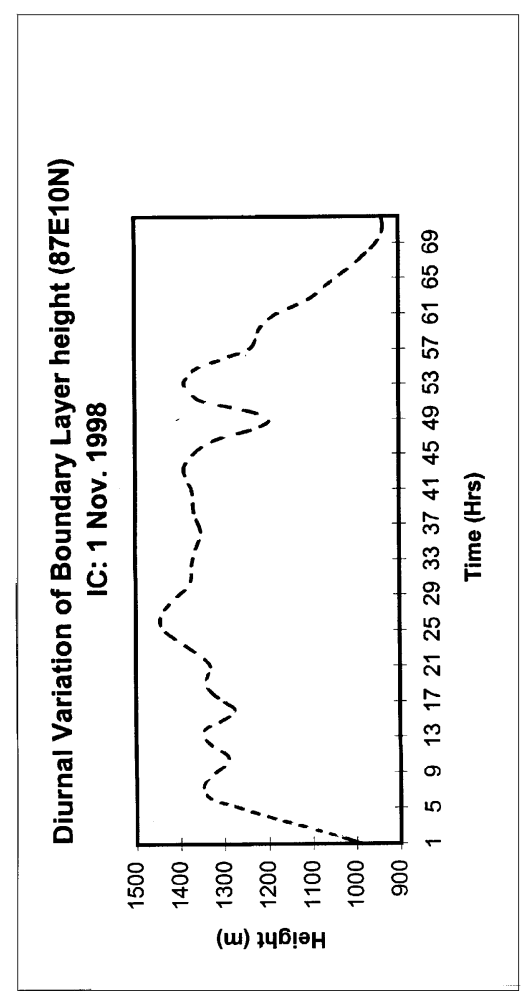

త

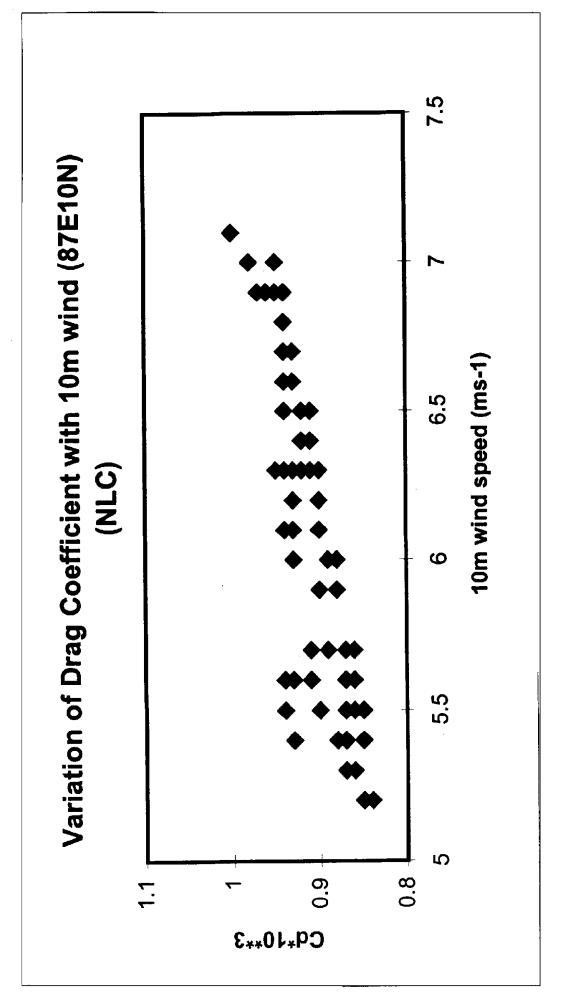

త્

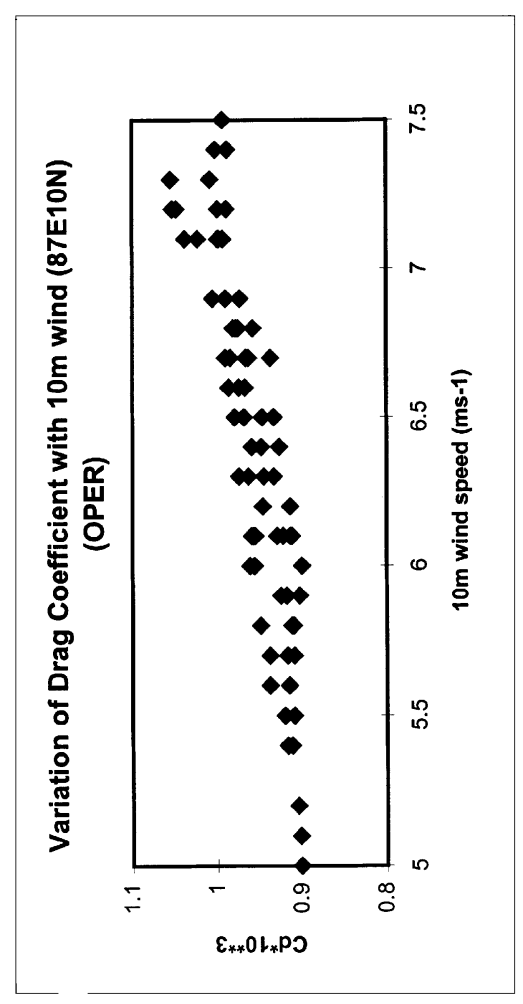

e

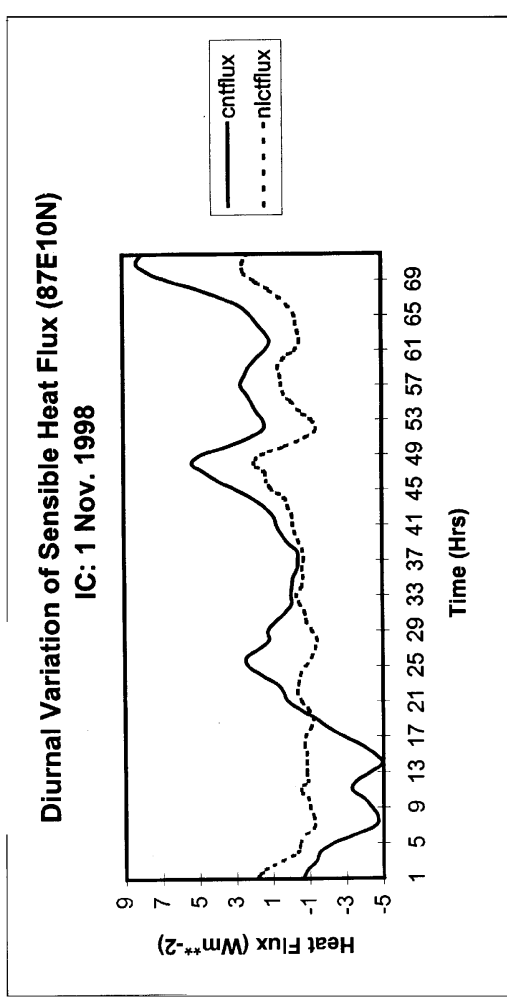

$\Theta$

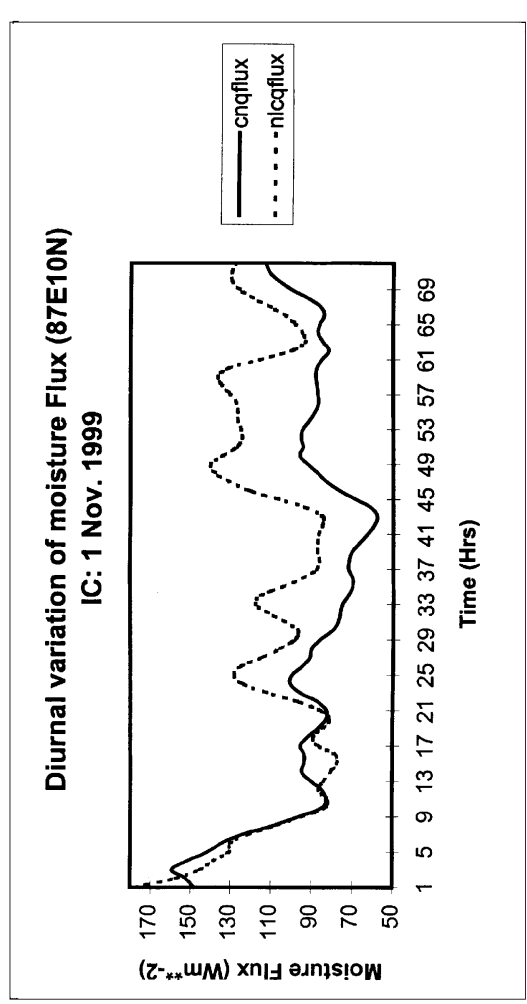

e

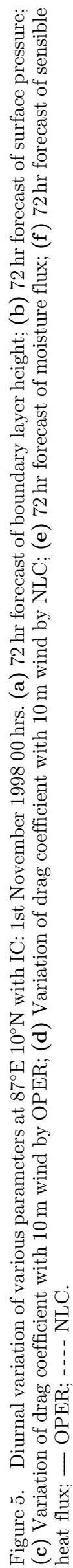


compared to OPER till about 500 meters, above which the reverse is true. This is apparent from the profiles of diffusivity which shows higher values at lower levels by NLC indicating efficient transport of humidity from the lower levels to the higher levels. Figure 5 (a)-(f) shows the diurnal variation of boundary layer height, surface pressure, heat and moisture fluxes along with variation of drag coefficients with $10 \mathrm{~m}$ winds using both NLC and OPER. Since OPER does not explicitly resolve the boundary layer height, the same is produced only by NLC. It is seen that the boundary layer height varies between $950 \mathrm{~m}$ and $1400 \mathrm{~m}$. Figure 5(b) shows the surface pressure by OPER and NLC which shows a drop in the same around $1300 \mathrm{hrs}$ of 1 st November. This may be attributed to the rainfall that occurred around that time. The variation by OPER and NLC is almost the same in magnitude. Figures $5(\mathrm{c})$ and (d) show the variation of drag coefficients with the winds at $10 \mathrm{~m}$ by OPER and NLC. Both the models show similar variation as well as similar values. As pointed out by Arya (1988) the dependence of the drag coefficients on $U_{10}$ is weak in the transition regime of wind speeds less than $7.5 \mathrm{~ms}^{-1} 2.5<U_{10}<7.5$. As seen from the figures, the wind speed at $10 \mathrm{~m}$ never exceed $7.5 \mathrm{~ms}^{-1}$. It is also seen that there is weaker dependence of the drag coefficients on $U_{10}$. The values are also comparable to those obtained in the moderate range of wind speeds (Kraus 1972) which is nearly constant and is around $1.2 \times 10^{-3}$. Garratt (1994) also shows similar variations as well as values within this wind speed range. Figures 5(e)-(f) show the diurnal variation of moisture and heat flux respectively by both the models. In general, both the models show high values of moisture flux $\left(150-170 \mathrm{Wm}^{-2}\right)$ which eventually is reduced after the rainfall. By and large NLC shows higher values of the flux compared to OPER. The sensible heat fluxes as expected are very small and the variations by both the models are similar and comparable.

\section{Conclusions}

Simulation of the marine boundary layer is obtained over the Bay of Bengal using two different schemes of the boundary layer for the BOBMEX-Pilot period. During the said period, both the flow pattern as well as the precipitation pattern were simulated reasonably well by both the models. OPER however had a tendency to enhance the circulation over the Bay and the corresponding precipitation patch. The flow patterns by and large compared reasonably with the verifying analysis. As far as the profiles in the boundary layer were concerned, the two situations of atmospheric conditions viz. cloudy during 1st November and the clear day for 3rd November were brought out by the models from the temperature profiles. Although the temperature profiles compared reasonably well with the observed one, the humidity profiles were under predicted for 1st November and over predicted for 3rd November which was a clear day. Winds simulated by the NLC for the clear day are almost constant with height and are less by about $2 \mathrm{~ms}^{-1}$ compared to OPER. The diffusivity profiles by both the models show differences in the lower levels. The differences in the simulation by the two models could be attributed to these differences in the diffusivity profiles which are mainly responsible for the distribution of the parameters in the vertical. Variation of surface parameters by both the models shows similar characteristics. The moisture flux in general is higher and sensible heat flux is lower as simulated by NLC compared to OPER. The boundary layer depth which varies between 900 and $1400 \mathrm{~m}$ is simulated by NLC which seemed to be in general agreement with observations (Bhat, personal communication). The variation of drag coefficients is also at par with general observations and both the models simulated similar features. Overall, based on the simulation of 1st November 1998, it was seen that by and large, both NLC and OPER performed in a similar manner. However, OPER had overestimated the circulation as well as the precipitation pattern compared to NLC as well as the verifying analysis and observations. In this respect, NLC had a slight edge over OPER. The surface parameter simulations did not show much variation using OPER and NLC except for the fluxes. The moisture fluxes simulated by NLC were more realistic. Further studies are on to assess the impact of two different schemes for PBL on the simulation of the marine boundary layer structure.

\section{Acknowledgement}

The author is grateful to the Head of Research Division and Head of NCMRWF for the encouragement and the support provided during the present work.

\section{References}

Arya S P S 1988 Int. Geophys. Series, 42, pp. 307

Ayotte K W 1996 Boundary-Layer Meteorol. 131-175

Basu Swati, Raman S, Mohanty U C and Rajagopal E N, 1999 PAGEOPH 33-55

Bhat G S, personal communication

Garratt J R 1994 The atmospheric boundary layer, pp. 316

Holtslag A A M, Boville B A, Bruijn J F and Pan H L 1990 Mon. Weather Rev. 1561-1575

Hong S Y and Pan H L 1989 Mon. Weather Rev. 1726-1750

Kraus E B 1972 Atmosphere-Ocean Interaction (Oxford University Press)

Mitra A K, Bohra A K and Rajan D, 1997 Int. J. Climatol. 1083-1092

Stull R B, 1984 J. Atmos. Sci. 3351-3367

Troen I and Mahrt L 1986 Boundary-Layer Meteorol. 129-148 